\title{
Fuzzy Decision Mechanism for Stock Market Trading
}

\author{
Yavuz Çapkan $^{1 *}$, Erdi Şenol ${ }^{2}$, Cenk Ulu ${ }^{3}$ \\ ${ }^{1}$ Yildiz Technical University, Faculty of Mechanical Engineering, Departmant of Mechatronics Engineering, Istanbul, Turkey (ORCID: 0000-0002-1901-6657), \\ yavuzcapkan@outlook.com \\ ${ }^{2}$ MEF University, Faculty of Engineering, Departmant of Electronic Engineering, Istanbul, Turkey (ORCID: 0000-0001-6260-7922), senole@ mef.edu.tr \\ ${ }^{3}$ Yildiz Technical University, Faculty of Mechanical Engineering, Departmant of Mechatronics Engineering, Istanbul, Turkey (ORCID: 0000-0002-8588-6247), \\ cenkulu@yildiz.edu.tr
}

(3rd International Congress on Human-Computer Interaction, Optimization and Robotic Applications June 11-13, 2021)

(DOI: $10.31590 /$ ejosat.951586)

ATIF/REFERENCE: Çapkan, Y., Şenol, E. \& Ulu, C. (2021). Fuzzy Decision Mechanism for Stock Market Trading. European Journal of Science and Technology, (26), 6-11.

\begin{abstract}
Investors utilize various methods to make buy/sell decisions depending on time-dependent stock market prices. In this study, a fuzzy decision mechanism that makes buy/sell decisions for stock market data is proposed. The proposed mechanism generates instant buy/sell decisions by evaluating three popular indicators which are the Moving Average Convergence/Divergence (MACD) Strategy, Chaikin Money Flow (CMF), and Stochastic Oscillator (SO). The fuzzy decision mechanism has three inputs and one output which are defined by using Gaussian membership functions. In the design of the decision mechanism, Mamdani inference method is used and the rule table is defined by nine rules. Therefore, the structure of the proposed fuzzy decision mechanism is simple and straightforward. The performance of the proposed fuzzy decision mechanism is compared with two classical decision mechanisms using MACD and CMF indicators separately. In the comparisons, the stock market data of Borsa Istanbul 100 Index (XU100), Dow Jones Industrial Average $\left({ }^{\wedge} \mathrm{DJI}\right)$, and S\&P $500\left(\wedge^{\mathrm{GSPC}}\right)$ are used. The comparison results show that the proposed fuzzy decision mechanism provides significantly higher profit than the mechanisms using either MACD or CMF indicators for all stock market data.
\end{abstract}

Keywords: Fuzzy logic, Stock market, Technical indicators, Technical analysis, XU100, ^DJI, ^GSPC.

\section{Hisse Senedi Piyasası için Bulanık Karar Mekanizması}

\section{Öz}

Yatırımcılar, hisse senedi/borsa değerlerinin zamana bağlı olarak alım/satım kararlarını vermek için çeşitli yöntemler kullanmaktadırlar. Bu çalışmada, hisse senedi piyasası verilerine ilişkin alım/satım kararlarını veren bir bulanuk karar mekanizması önerilmiştir. Önerilen çıkarım mekanizması üç popular gösterge olan Hareketli Ortalama Yakınsama/Iraksama (MACD), Chaikin Para Akışı (CMF) ve Stokastik Osilatör (SO) göstergelerini değerlendirerek anlık alım/satım kararları üretmektedir. Bulanık karar mekanizmasının, Gauss üyelik fonksiyonları kullanılarak tanımlanmış üç adet girişi ve bir adet çıkışı vardır. Karar mekanizmasının tasarımında Mamdani çıkarım yöntemi kullanılmış ve kural tablosu dokuz kural ile tanımlanmıştır. Bu nedenle, önerilen bulanık karar mekanizmasının yapısı basit ve anlaşılırdır. Önerilen bulanık karar mekanizmasının performansı, MACD ve CMF göstergelerini ayrı ayrı kullanan iki klasik karar mekanizması ile karşılaştırılmıştır. Karşılaştırmalarda Borsa Istanbul 100 Endeksi (BIST100), Dow Jones Borsası Endüstri Endeksi (^DJI) ve S\&P $500\left(\wedge^{\wedge} \mathrm{GSPC}\right)$ borsa verileri kullanılmıştır. Karşılaştırma sonuçları, önerilen bulanık karar mekanizmasının tüm borsa verileri için MACD veya CMF göstergelerini kullanan klasik karar mekanizmalarından önemli ölçüde daha yüksek kar sağladığını göstermektedir.

Anahtar Kelimeler: Bulanık mantık, Borsa, Teknik göstergeler, Teknik analiz, BIST100, ^DJI, ^GSPC.

* Corresponding Author: yavuzcapkan@ outlook.com 


\section{Introduction}

New formulas, techniques, and different approaches have been tried to increase earnings in the stock market for years. The common feature of all stock markets is that they include uncertainties in the short or long term. Although the irregular fluctuations in prices make some investors lose money, some investors increase their profit by using different methods to predict uncertainty in prices (Adebiyi, 2011). These methods are fundamental analysis, technical analysis, time series analysis, and machine learning methods (Altay \& Satman, 2005). Today, investors use one or more of these methods at the same time in order to predict possible or extraordinary price fluctuations. In the fundamental analysis, investors analyze the trend over a certain time using lines. It is determined whether the stock market is in a downward or upward trend with this analysis method. In the basic analysis method, investors analyze the assets and debts of the company and estimate the future status of the stock market price. In the classical time series analysis, the model of the price change of the stock market in time is derived by utilizing previous price data and, the future prices are estimated. Similarly, machine learning methods are also used to derive more accurate models (Altunkaynak, 2010), (Atiya et al, 1997), (Atsalakıs et al, 2015). Investors generally make their decisions by using trend, volume, and demand information. Although these types of information are easy to use alone, they provide insufficient performance. Therefore, they are used with additional decision mechanisms to make more accurate decisions (Avci, 2007).

Ahmed et al., introduced a fuzzy logic-based stock market decision mechanism (Gamil et al, 2007). They tested the system with the NASDAQ index data. However, they only used the Moving Average (MA) technical indicator in the rules for the fuzzy inference system. Boyacioglu and Avci proposed a predictive system by modeling the stock market index with ANFIS (Adaptive Neuro Fuzzy Inference System) (Boyacioglu \& Avci, 2010). They tested their system on the XU100 index. Ijegwa et al. introduced a fuzzy logic-based stock market decision mechanism. They used 4 indicators in their study and tested them with data from two Nigerian banks (Achema et al, 2014). Su and Cheng proposed a new ANFIS (Adaptive Neuro Fuzzy Inference System) time series model based on the INFS (integrated nonlinear feature selection) method ( $\mathrm{Su} \&$ Cheng, 2016). Naranjo et al., introduced a methodology to detect candlestick patterns in a stock market trading system using fuzzy logic (Naranjo et al, 2018). In their study, they made comparisons using TAIEX and HIS stock market data. Lauguico et al. proposed an algorithm that goes through a specific trading strategy using three fuzzy logic controllers (Lauguico et al, 2019). They tested and compared the system in two portfolios of the Nasdaq-100 and Eurostoxx market. Huang et al. represented a new trading point prediction framework that includes the dualcluster mining technique, a method for establishing the fuzzy rule base, and a fuzzy inference system optimized for trade point prediction (Huang et al, 2020). They tested the system using technical indicators such as candlestick parameters and Bollinger Bands (BB) to trigger the strength of buy, hold, and sell signals. They named their method BM-FM and tested it with stock market data.

In literature, most of the existing methods handle the problem within the time series prediction framework. After these prediction processes, additional analyses are needed to make a buy/sell decision. On the other hand, the existing methods providing buy/sell decisions are not easily applicable due to their quite complex structures. In this study, a decision mechanism is proposed to provide appropriate instant buy/sell decisions for stock market data. The proposed mechanism is based on the fuzzy inference system which uses three popular indicators as inputs. These indicators are the Moving Average Convergence Divergence (MACD) Strategy, Chaikin Money Flow (CMF), and Stochastic Oscillator (SO). It is aimed to increase the earnings by using buy/sell decisions of the proposed mechanism. The proposed decision mechanism is designed in a simple and straightforward structure in order to obtain effective results in many different stock market data. The effective performance of the proposed fuzzy decision mechanism is demonstrated on three different stock market data which are XU100, ^^DJI, and ${ }^{\wedge} \mathrm{GSPC}$ data.

The organization of this study is as follows. In Section 2, the indicators used in this study are given. In Section 3, the proposed fuzzy decision mechanism is introduced. In Section 4, experiment results are demonstrated. Finally, the conclusions are summarized in Section 5.

\section{Indicators Used in The Study}

\subsection{MACD (Moving Average Convergence / Divergence)}

The MACD was introduced by Gerald Appel in the 1970s. The MACD is based on moving averages and is mainly designed to identify trend changes. It is calculated by subtracting a longer Exponential Moving Average (EMA) from a shorter EMA (Appel \& Dobson, 2008), (Rosillo et al, 2013).

EMA and MACD are defined as follows

$$
\begin{aligned}
& E M A_{n}(i)=\operatorname{Value}(i) *\left(\frac{2}{1+n}\right)+E M A_{n}(i-1) *\left(1-\left(\frac{2}{1+n}\right)\right)(1) \\
& M A C D(n)=\sum_{i=1}^{n} E M A_{a}(i)-\sum_{i=1}^{n} E M A_{b}(i)
\end{aligned}
$$

where, $n$ is the number of days, and Value $(i)$ is the asset price on an $i^{\text {th }}$ day. After the calculations of EMA and MACD, the signal and histogram values are calculated as follows.

$\operatorname{Signal}(n)=S M A_{9}(M A C D(n))$

$\operatorname{MACDHistogram}(n)=\operatorname{MACD}(n)-\operatorname{Signal}(n)$

Signal in (3) gives the exponential average of another 9 days and is used to see the long and short opportunities placed above the MACD. SMA is the Simple Moving Average and, the histogram is the distance between the MACD line and the signal line.

\subsection{SO (Stochastic Oscillator)}

The Stochastic Oscillator was developed by George Lane in the late 1950s. SO refers to the point of a current price about the price range of a stock market over a specified period of time. This method tries to predict price turning points by comparing the closing price with the price range (Murphy, 1999).

The future trend of the stock market is shown by using the difference between the maximum and minimum closing prices in the specified periods. SO is represented by two different lines; the short time line $\% D$ and the long time line $\% K$. These values are calculated as follows 
$\% K=\frac{\text { Close }-\operatorname{Low}_{x}}{\operatorname{High}_{x}-\operatorname{Low}_{x}} * 100$

$\% D(n)=S M A_{3}(\% K(n))$

where, $x$ represents the number of previous trading sessions.

\subsection{CMF (Chaikin Money Flow)}

Chaikin Money Flow was developed by Marc Chaikin. CMF measures the volume of money flow over a specified period of time. CMF is the basis of the accumulation distribution line. Instead of cumulative total money flow volume, the CMF aggregates only the money flow volume for a given past period. To determine changes in money flow, signals above or below the zero line are checked (Thomsett, 2010), (Cohen, 2020). CMF is calculated as follows

$C M F=\frac{M F V}{\text { Volume }_{n}}$

Here MFV indicates Money Flow Volume and $n$ is the sum of the volume in a certain period. MFV is determined as follows

$M F V=M F M *$ Volume

$\% M F M=\frac{(\text { Close }- \text { low })-(\text { High }- \text { Close })}{\text { High }- \text { Low }}$

where MFM is Money Flow Multiplier.
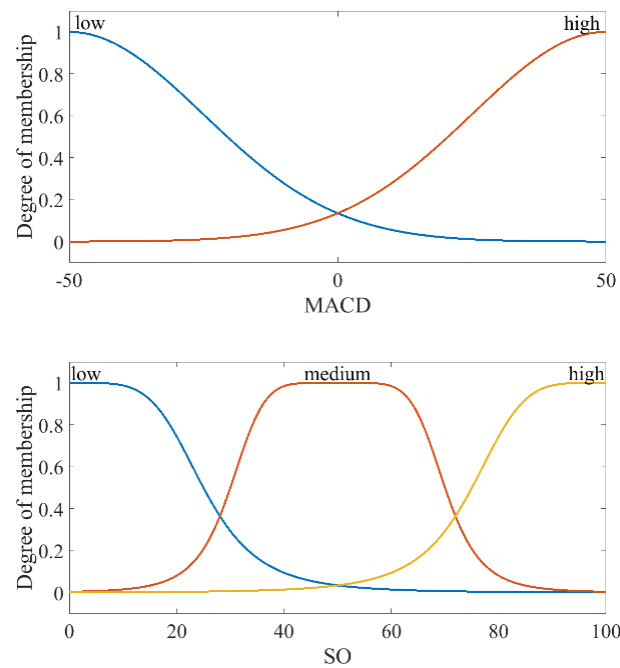

\section{Proposed Fuzzy Decision Mechanism}

In this section, the proposed fuzzy decision mechanism is given. In the design of the decision mechanism, Mamdani inference method is used (Mamdani \& Assilian, 1975). The proposed fuzzy decision mechanism uses three popular indicators as inputs which are MACD, CMF, and SO. The output range is defined as [-1 1]. If the output value is less than 0 , it is evaluated as a sell. On the other hand, if it is greater than 0 , it is considered as a buy. In the graphical representation of buy/sell values, buy and sell signals are created in the changes from the status of - (minus) to + (plus) or vice versa. Situations other than these signals are considered as a hold.

The input range for MACD is determined as [-50 50]. 12 and 26 days EMAs are used to calculate the MACD data. The range of the CMF indicator is chosen as [-1 1], and in the calculation of the CMF indicator, $n=1$ is used. The range of the SO indicator is determined between 0 and 100. $x=5$ trading session is used in the calculation of the SO indicator. The output interval of the fuzzy decision mechanism is determined as [-1 1]. Gaussian membership functions are used for all input and output variables as shown in Fig. 1, respectively.

The constructed rule table with 9 rules is given in Table 1. Depending on the final design of the proposed mechanism, the obtained decision surfaces for MACD-CMF, MACD-SO, and CMF-SO are shown in Fig. 2 respectively.
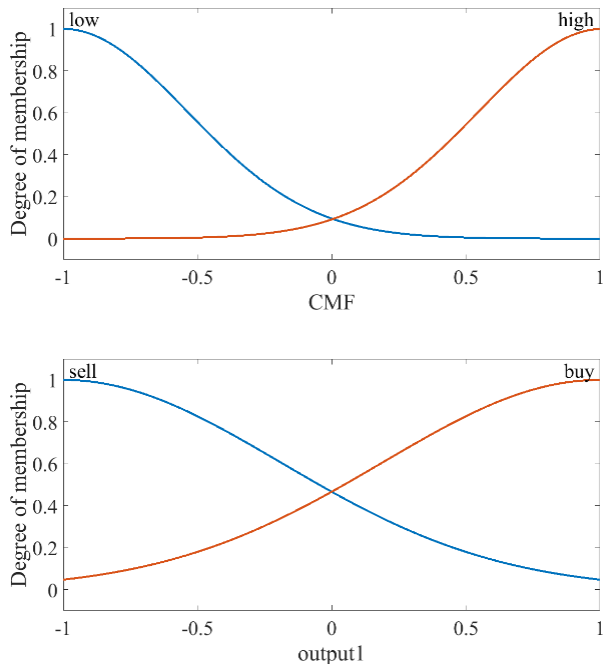

Figure 1.Inputs and output membership functions.

Table 1. Fuzzy rules

\begin{tabular}{l|c|c|c|c}
\hline Rule Number & MACD & CMF & SO & Output \\
\hline 1 & high & high & low & buy \\
\hline 2 & high & low & high & sell \\
\hline 3 & low & high & low & buy \\
\hline 4 & low & low & low & sell \\
\hline 5 & high & high & medium & buy \\
\hline 6 & low & low & medium & sell \\
\hline 7 & high & high & high & buy \\
\hline 8 & low & high & high & buy \\
\hline 9 & low & low & high & sell \\
\hline & \multicolumn{3}{|l}{}
\end{tabular}



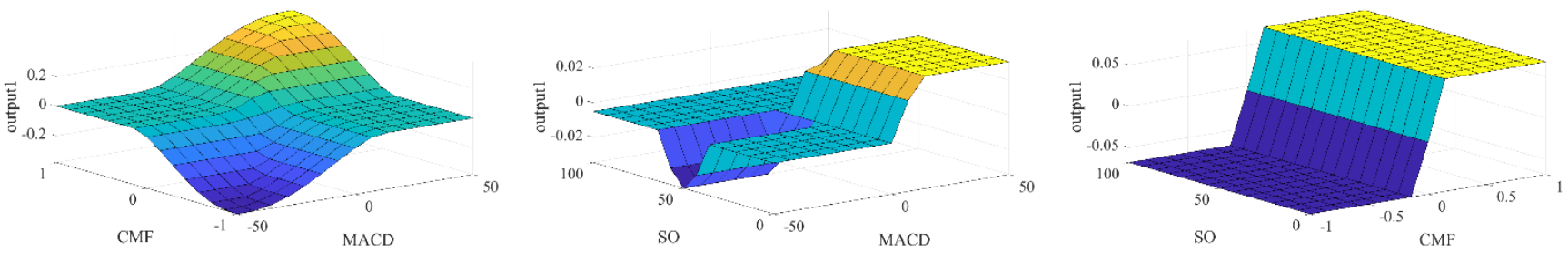

Figure 2. Fuzzy surfaces for MACD-CMF, MACD-SO and CMF-SO.

\section{Experiment Results}

In this section, the proposed fuzzy decision mechanism is tested by using three different market data which are XU100, ${ }^{\wedge}$ GSPC, and ${ }^{\wedge} \mathrm{DJI}$. To show the effectiveness of the proposed mechanism, the performance of the proposed fuzzy decision mechanism is compared with two classical decision mechanisms using MACD and CMF indicators separately.

Firstly, indicators are calculated in order to be applied to the fuzzy decision mechanism. Then, the proposed fuzzy decision mechanism generates the buy or sell decisions by evaluating these indicator values. The dates between 28 December 2010 and 13 November 2020 (2486 trading days) are used for XU100 data which is downloaded from investing.com. The data between 1 January 2016, and 8 January 2021 are used for ${ }^{\wedge}$ GSPC and ${ }^{\wedge}$ DJI stock market data from Yahoo. Since no result is produced for the first 33 days in MACD indicator calculation, 33 days before the initial dates are also considered for MACD indicator. The graphical representations of XU100, ^ $\mathrm{GSPC}$, and ${ }^{\wedge} \mathrm{DJI}$ stock market data are shown in Fig. 3, 4, and 5, respectively (Graphics dates (Fig. 4 and 5): 1 September 2020 - 8 January 2021).

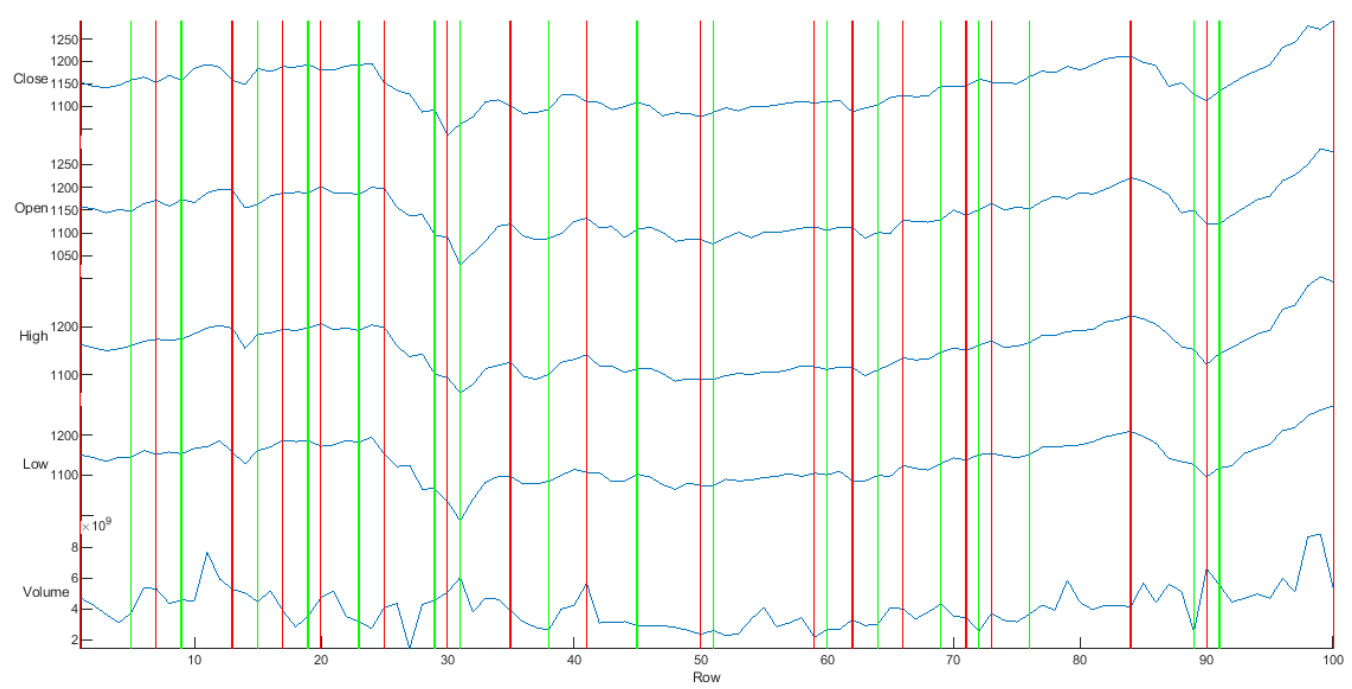

Figure 3. XU100 graphical representation of 100-day buy/sell points (Green: buy, Red: sell).



Figure 4. ^GSPC graphical representation with buy/sell points (Green: buy, Red: sell). 


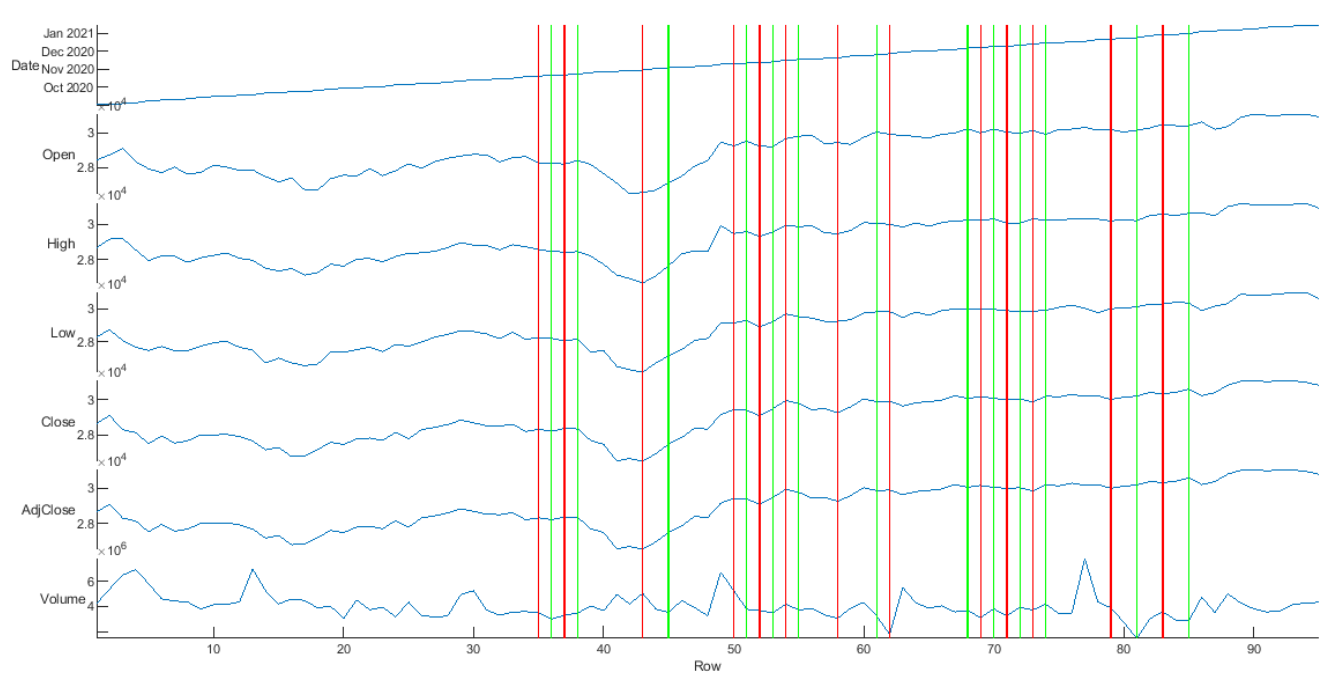

Figure 5. ^DJI graphical representation with buy/sell points (Green: buy, Red: sell).

Buy/sell signals are generated for all decision mechanisms when the output is changed from - (minus) to + (plus) or vice versa. Determined buy and sell points are shown with the green (buy) and red (sell) vertical lines in Fig. 3, 4, and 5 for all test data. Then, the closing price in the sell signal is subtracted from the closing price in the buy signal. Finally, the total profit/loss is determined by using (10) - (14) given below. Unit stock market data price is used for calculating the profit, and the total profit is calculated by adding the profits obtained by trading with the unit price. In the calculations, the first buy decision and the last sell decision are not taken into consideration.

$J_{n}= \begin{cases}\text { Buy } & \text { if } I_{n}>0, \text { else if } I_{n-1}<0 \\ \text { Sell } & \text { if } I_{n}<0, \text { else if } I_{n-1}>0\end{cases}$

$K_{n}=\left\{\begin{array}{cc}C_{n} & \text { if } J_{n}==" B u y " \\ K_{n-1} & \text { else }\end{array}\right.$

$L_{n}=\left\{C_{n} \quad\right.$ if $J_{n}=="$ Sell"

$M_{n}=\left\{L_{n}-K_{n} \quad\right.$ if $J_{n} \neq " "$

$N=\operatorname{SUM}\left(N_{x}: N_{y}\right)$

- C: Close price

- I: Output (Fuzzy, MACD, CMF)

- J: Buy/Sell decision

- $\mathrm{K}$ : Buy price

- L: Sell price

- M: Profit

- N: Total Profit

- $\mathrm{n}$ : Column number

- $\quad \mathrm{x}$ : start of profit calculation

- $\quad \mathrm{y}$ : end of profit calculation

The comparison of the calculated total profits is given in Table 2 for all test data.

Table 2. The total profit comparison

\begin{tabular}{l|c|c|c}
\hline & Fuzzy & MACD & CMF \\
\hline XU100 & 856.36 & 678.43 & 625.65 \\
\hline${ }^{\wedge}$ DJI & 16523.26 & 9748.31 & 7001.61 \\
\hline${ }^{\wedge}$ GSPC & 1075.47 & 937.29 & 689.37 \\
\hline
\end{tabular}

As it is seen from Table 2, for XU100 stock market data, the proposed fuzzy decision mechanism provides $26.23 \%$ and $36.88 \%$ higher profit than the decision strategies based on either MACD or CMF indicators, respectively. When the results for ${ }^{\wedge}$ DJI market data are considered, the fuzzy decision mechanism has the best performance by providing $69.50 \%$ and $135.99 \%$ higher profit than the decision strategies based on either MACD or CMF indicators, respectively. Similarly, when the performances are evaluated for ${ }^{\wedge} \mathrm{GSPC}$ market data, the proposed fuzzy decision mechanism provides $14.74 \%$ higher profit than the decision strategy based on MACD indicator and $56.01 \%$ higher profit than the decision strategy based on $\mathrm{CMF}$ indicator.

\section{Conclusions}

This study presents a new decision mechanism based on the fuzzy inference approach for stock market trading applications. The proposed fuzzy decision mechanism uses three popular indicators as inputs which are MACD, CMF, and SO to provide instant buy/sell decisions. The proposed fuzzy decision mechanism is tested on XU100, ${ }^{\wedge} \mathrm{DJI}$, and ${ }^{\wedge}$ GSPC stock market index data. The results clearly show that the proposed mechanism provides higher profit than the decision strategies using either MACD or CMF indicators alone.

The structure of the proposed decision mechanism is simple and straightforward. Therefore it can easily be used for other stock market index data. Higher performance can be obtained for different stock market index data by tuning the membership functions of the proposed mechanism. Additionally, the proposed decision mechanism can easily be combined with the existing time series prediction algorithms to provide long term buy/sell decisions.

In future studies, it is aimed to carry out optimization studies for the proposed decision mechanism in order to increase the performance of the mechanism.

\section{References}

Acheme, D., Vincent, O., Folorunso, O. and Isaac, O. (2014). A predictive stock market technical analysis using fuzzy logic, 
Computer and Information Science 7. doi: 10.5539/cis.v7n3p1.

Adebiyi, A. A., Ayo, C.K. and Otokiti S.O. (2011). Fuzzy-neural model with hybrid market indicators for stock forecasting, Int. J. Electron. Financ. 5 (3), 286-297. doi: 10.1504/IJEF.2011.041342.

Altay, E. and Satman, M.H. (2005). Stock market forecasting: Artificial neural networks and linear regression comparison in an emerging market, Journal of Financial Management and Analysis 18(2), 18-33.

Altunkaynak, A. (2010). A predictive model for well loss using fuzzy logic approach. Hydrol. Process., 24: 2400-2404. https://doi.org/10.1002/hyp.7642.

Appel, G. and Dobson, E. (2008). Understanding MACD (Moving Average Convergence Divergence), Traders Press, Inc.

Atiya, A., Talaat, N. and Shaheen, S. (1997). An efficient stock market forecasting model using neural network, in: Proceedings of International Conference on Neural Networks, pp. 2112-2115.

Atsalakıs, G., Protoparadakıs, E. and Valavanıs, K. (2015). Stock trend forecasting in turbulent market periods using neurofuzzy systems, Oper Res Int J 16, 245-269doi: 10.1007/s12351-015-0197-6.

Avc1, E. (2007). Forecasting daily and sessional returns of the ise-100 index with neural network model, Journal of Dogus University 8(2), 128-142.

Boyacioglu, M. and Avci, D. (2010). An adaptive network-based fuzzy inference system (anfis) for the prediction of stock market return: The case of the istanbul stock exchange, Expert Systems with Applications 37, 7908-7912. doi: 10.1016/j.eswa.2010.04.045.

Cohen, G. (2020). Algorithmic setups for trading popular u.s. etfs, Cogent Economics \& Finance 8 (1), 1720056. doi: 10.1080/23322039.2020.1720056.

Gamil, A., Elfouly, R.S. and Darwish, N. (2007). Stock technical analysis using multi agent and fuzzy logic, in: World Congress on Engineering.

Huang, Q., Yang, J., Feng, X., Liew, A.W. and Li, X. (2020). Automated trading point forecasting based on bicluster mining and fuzzy inference, IEEE Transactions on Fuzzy $\begin{array}{llll}\text { Systems } & 28 & \text { (2), } & \text { 259-272. }\end{array}$ 10.1109/TFUZZ.2019.2904920.

Lauguico, S., Concepcion II, R., Alejandrino, J., Macasaet, D., Tobias, R.R., Bandala, A. and Dadios, E. (2019). A fuzzy logic-based stock market trading algorithm using bollinger bands, in: 2019 IEEE 11th International Conference on Humanoid, Nanotechnology, Information Technology, Communication and Control, Environment, and Management (HNICEM), pp. 1-6. doi: 10.1109/HNICEM48295.2019.9072734.

Mamdani, E. and Assilian, S. (1975). An experiment in linguistic synthesis with a fuzzy logic controller, International Journal of Man-Machine Studies 7 (1), 1-13. doi: https://doi.org/10.1016/S0020-7373(75)80002-2.

Murphy, J.J. (1999). Technical Analysis of the FinancialMarkets, Institute of Finance, New York.

Naranjo, R., Arroyo, J. and Santos, M. (2018). Fuzzy modeling of stock trading with fuzzy candlesticks, Expert Systems with Applications 93, 15-27. doi: 10.1016/j.eswa.2017.10.002.

Rosillo, R., Fuente, D. and Brugos, José A. (2013). Technical analysis and the Spanish stock exchange: testing the RSI,
MACD, momentum and stochastic rules using Spanish market companies. Applied Economics. 45. 1541-1550. 10.1080/00036846.2011.631894.

Su, C.H. and Cheng, C.H. (2016). A hybrid fuzzy time series model based on anfis and integrated nonlinear feature selection method for forecasting stock, Neurocomputing 205, 264-273. doi: 10.1016/j.neucom.2016.03.068.

Thomsett, M.C. (2010). CMF-Chaikin Money Flow: Changes Anticipating Price Reversal, FT Press. 